\title{
Increased Lactate in Gastric Cancer Tumor- Infiltrating Lymphocytes Is Related to Impaired T Cell Function Due to miR-34a Deregulated Lactate Dehydrogenase A
}

\author{
Wang Ping ${ }^{\mathrm{a}}$ Hu Senyan ${ }^{\mathrm{b}} \quad$ Gu Lia Chen Yan ${ }^{\mathrm{a}}$ Lu Long ${ }^{\mathrm{b}, \mathrm{c}}$ \\ aDepartment of Endocrinology, People's Hospital of Gaochun, Nanjing, bepartment of Surgery, \\ People's Hospital of Gaochun, Nanjing, 'Department of Surgery, Nanjing Jiangbei People's Hospital, \\ Nanjing, China
}

\section{Key Words}

Lactate $\bullet$ Lactate dehydrogenase A $\cdot$ miR-34a $\bullet$ Th1 cells $\bullet$ Cytotoxic T lymphocytes

\begin{abstract}
Background/Aims: Lactate is one of the products of glycolysis and is a hallmark of the Warburg effect. Glycolysis is found in tumor as well as immune cells. However, the effects of lactate on the function of tumor-infiltrating T cells (TILs) are rarely reported. Methods: In the present study, we investigated lactate and other glycolysis-related metabolites within TILs of human gastric cancer (GC). Lactate concentration was determined by liquid chromatographymass spectrometry. The functional effects and clinical relevance of excessive lactate on T cells were investigated in clinical samples, and the mechanism of increased lactate was explored. Results: Lactate was significantly increased in GC TILs and related to decreased T helper (Th)1 cells and cytotoxic T lymphocytes (CTLs). Increased lactate within GC TILs was positively correlated with increased lactate dehydrogenase A (LDH)A. Expression of LDHA in GC TILs was also negatively correlated with percentages of Th1 cells and CTLs. Decreased miR-34a expression in GC TILs was responsible for increased expression of LDHA. A hypoxic tumor environment was responsible for decreased miR-34a and lactate-induced impaired immune function. Conclusion: We found that hypoxia decreases miR-34a expression and lose miR34a regulation on LDHA, thus increasing lactate level within GC TILs and impairing immune function in GC.
\end{abstract}

\section{Introduction}

The Warburg effect is the observation that most cancer cells predominantly produce energy by a high rate of glycolysis followed by lactate fermentation in the cytosol, rather than by a comparatively low rate of glycolysis followed by oxidation of pyruvate in mitochondria as in most normal cells $[1,2]$. So, frequently there is an acidic tumor microenvironment (TME),

\begin{tabular}{ll}
\hline Dr. Lu Long & Department of Surgery, People's Hospital of Gaochun \\
& 9 ChunZhong Rd, GaoChun, Nanjing, Jiangsu, 211300 (China) \\
& E-Mail drlvlonggc@outlook.com
\end{tabular}


especially in solid tumors, that affects the cells in the tumor microenvironment as well as the tumor cells $[1,3]$. Many previous studies have revealed that lactate might have serious effects on the tumor-infiltrating immune cells, and decrease their immune surveillance by various mechanisms $[4,5]$.

The TME is the cellular environment in which the tumor exists, including surrounding blood vessels, immune cells, fibroblasts, bone-marrow-derived inflammatory cells, lymphocytes, signaling molecules and the extracellular matrix [6, 7]. Metabolites and recently highlighted factors regulating tumor-TME cell interaction are important elements in the TME $[1,8]$. Previous studies have revealed that activation of $\mathrm{T}$ and $\mathrm{B}$ cells results in altered metabolism. For example, activation of T cells needs both glycolysis and glutaminolysis [9], but activation of B cells does not completely switch oxidative phosphorylation to glycolysis, instead of using both pathways [10]. Activation of both T and B cells requires glycolysis and lactate production, which indicates that $\mathrm{T}$ and $\mathrm{B}$ cell activation contributes to the acidic environment of the tumor.

In our preliminary study, we found that lactate concentration was significantly increased in gastric cancer tumor-infiltrating lymphocytes (GC TILs), and increased lactate level was negatively related to proinflammatory T cells [T helper (Th)1 and cytotoxic lymphocytes (CTLs)]. Our results were similar to those in a recent publication indicating that excessive lactate in melanoma impaired T-cell activation by inhibiting nuclear factor of activated T cells (NFAT) [11]. Therefore, in the present research, we investigated the reasons for increased lactate in GC TILs that might relate to increased lactate dehydrogenase (LDH)A, and explored the mechanism of increased LDHA in GC TME.

\section{Materials and Methods}

\section{Patients and sample preparation}

We included 73 GC cases and 58 sex- and age-matched controls from Gaochun Hospital, China. Patients were consecutively recruited between January 2012 and October 2016 . All cases are incident once during enrollment of the current case-control study. The diagnosis of all patients was pathologically confirmed. A face-to-face questionnaire was administered to all patients to collect demographic data. Written informed consent was obtained from all participants. This study was approved by the Institutional Review Board of Gaochun Hospital.

\section{Cell lines and reagents}

Jurkat cell line was purchased from The Cell Bank of the Chinese Academy of Sciences. The cell line was maintained in a humidified atmosphere of $5 \% \mathrm{CO}_{2}$ at $37^{\circ} \mathrm{C}$. Lactate was purchased from Sigma-Aldrich. Hypoxia was generated using a hypoxic incubator (Heracell ${ }^{\mathrm{TM}} 150 \mathrm{i}$ and $240 \mathrm{i}$ Tri-Gas Incubators; Thermo Fisher Scientific) for $48 \mathrm{~h}$.

Isolation of Tumor infiltrated T cells

Fresh TILs were obtained as described previously [12]. Cancer and peritumoral tissues were cut into small pieces and digested in $100 \mathrm{U} / \mathrm{ml}$ collagenase type IV and $100 \mu \mathrm{g} / \mathrm{ml}$ DNase in RPMI + 10\% fetal bovine serum (FBS; Gibco) in RPMI 1640. Dissociated cells were filtered through a 75- $\mu \mathrm{m}$ cell strainer and separated by Ficoll centrifugation. The mononuclear cells were washed and resuspended in RPMI 1640 supplemented with $10 \%$ FBS. For peripheral T cells, the mononuclear cells were isolated using Ficoll centrifugation. TILs and peripheral T cells were purified with anti-CD3 magnetic Dynabeads (Thermo Fisher).

\section{Sample preparation and metabolomics determination}

Ice-cold 50\% methanol $(5 \mathrm{ml})$ and $1 \mathrm{ml}$ acetonitrile-methanol-water $(4: 4: 2, \mathrm{v} / \mathrm{v})$ was added to resuspend and extract the $\mathrm{T}$ cells, respectively. All the cells were broken up by ultrasonication for $10 \mathrm{~min}$ $(300 \mathrm{~W})$. The supernatant was obtained by centrifugation at $4000 \mathrm{rpm}$ for $15 \mathrm{~min}$. Metabolite extraction was subsequently carried out to isolate metabolites from the freeze-dried supernatant. Methanol $(100 \mu \mathrm{l})$ was added to redissolve samples that were vortexed for $30 \mathrm{~s}$, followed by centrifugation $(12000 \mathrm{rpm}, 15$ $\min$ ) at $4^{\circ} \mathrm{C}$. The supernatant was used for detection.

Metabolic profiling was performed on a UPLC Ultimate 3000 system (Dionex, Germering, Germany), coupled to an Orbitrap mass spectrometer (Thermo Fisher Scientific, Bremen, Germany) in both positive and negative mode simultaneously. The chromatographic separation was performed on a 1.9- $\mu$ m Hypersile Gold C18 column (100 mm $\times 2.1 \mathrm{~mm}$ ) (Thermo Fisher Scientific), and the column was maintained at $40^{\circ} \mathrm{C}$. A multistep gradient had a mobile phase A of $0.1 \%$ formic acid in ultrapure water and mobile phase B

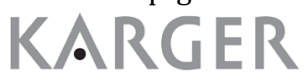




\section{Cellular Physiology Cell Physiol Biochem 2018;49:828-836

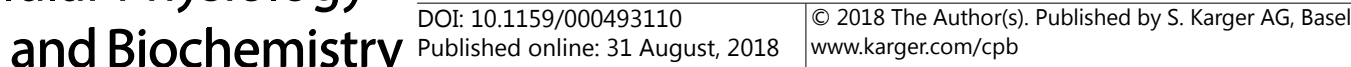 \\ Ping et al.: miR-34a Regulate GC T Cell via LDHA}

consisting of acetonitrile acidified with $0.1 \%$ formic acid. The gradient operated at a flow rate of $0.4 \mathrm{ml} /$ min over a run time of $15 \mathrm{~min}$. The UPLC autosampler temperature was set at $4^{\circ} \mathrm{C}$, and the injection volume for each sample was $10 \mu \mathrm{l}$. For both positive and negative mode, the operating parameters were as follows: spray voltage of $3.5 \mathrm{kV}$ for positive, $2.5 \mathrm{kV}$ for negative, capillary temperature of $300^{\circ} \mathrm{C}$, sheath gas flow of 50 arbitrary units, and auxiliary gas flow of 13 arbitrary units.

\section{Real-time PCR}

The total RNA of TILs was isolated with TRIzol reagent (Thermofisher). cDNA was synthesized using a Bio-Rad iScript Reverse Transcription Supermix for RT-qPCR. Expression of LDHA, LDHB, interferon (IFN)- $\gamma$ as well as granzyme (GZM)B was detected using an SsoAdvanced ${ }^{\mathrm{TM}}$ Universal SYBR® Green Supermix, using the following primers: LDHB: ATGGCAACTCTAAAGGATCAGC, CCAACCCCAACAACTGTAATCT, 86 bp; LDHB: TGGTATGGCGTGTGCTATCAG,TTGGCGGTCACAGAATAATCTTT,171bp;IFN- $\gamma$ :TCGGTAACTGACTTGAATGTCCA, TCGCTTCCCTGTTTTAGCTGC, 93 bp; GZMB: CCCTGGGAAAACACTCACACA, GCACAACTCAATGGTACTGTCG, $110 \mathrm{bp}$, and $\beta$-actin: CATGTACGTTGCTATCCAGGC, CTCCTTAATGTCACGCACGAT, $250 \mathrm{bp}$. The relative expression of genes indicated above was obtained using the $2^{-\Delta \Delta C t}$ methods.

\section{Western blotting}

Proteins were extracted from tissues or cultured cells using RIPA buffer containing phenylmethanesulfonylfluoride (Beyotime, Nantong, China). Equal amounts of protein (100 $\mu \mathrm{g})$ were separated by SDS-PAGE on a 7.5\%/12.5\% gel and transferred to a polyvinylidene difluoride membrane. Primary polyclonal antibodies were purchased from Abcam (Cambridge, MA, USA): LDHB (ab142349), IFN- $\gamma$ (ab87099) and $\beta$-actin (ab8227). The secondary antibodies used were horseradish-peroxidaseconjugated anti-rabbit or anti-mouse antibodies were purchased from Santa Cruz Biotechnology. The blots were developed using ECL reagent (Millipore, Billerica, MA, USA). An equal amount of loaded protein in each lane was confirmed using a $\beta$-actin antibody. Image J software was used to quantify the integrated density of the band.

\section{Immunohistochemistry staining}

Tissue sections were deparaffinized and rehydrated with a graded ethanol series and distilled water, and then treated with $3 \% \mathrm{H}_{2} \mathrm{O}_{2}$ in methanol for 30 min to block endogenous peroxidase activity. Tissue sections were then rinsed twice for 5 min in phosphate-buffered saline (PBS) and incubated with $10 \%$ normal goat serum for $30 \mathrm{~min}$ to block nonspecific antibody binding. After washing, the samples were incubated with a primary anti-rabbit antibodies (Abcam) against LDHB (ab142349), IFN- $\gamma$ (ab87099) and GZMB (ab2486) ) at $4^{\circ} \mathrm{C}$ overnight. Sections were washed in PBS three times and incubated with secondary antibodies. The sections were stained with diaminobenzidine, mounted on slides, and photographed using a digital microscope camera (Nikon, Tokyo, Japan).

\section{Flow cytometry detection}

The magnetic beads isolated T cells were maintained in the T cell medium (GT-T551 Medium for T-Cell Culture and Expansion; TaKaRa) and stimulated with Leukocyte Activation Cocktail, with BD GolgiPlug ${ }^{\mathrm{TM}}$ (BD Pharmingen) for $4 \mathrm{~h}$. The cells were fixed and permeabilized with Fixation and Permeabilization Solution (BD Pharmingen). The cells were analyzed with a LIVE-OR-DYE ${ }^{\mathrm{TM}}$ 350/448 Fixable Viability Staining Kit (Thermo Fisher) and stained using antibodies against: CD4 (PE, Mouse, Anti-Human, CD4, 555347), CD8 (FITC, Mouse, Anti-Human, CD8, 560960), and IFN- $\gamma$ (APC Mouse Anti-Human IFN- $\gamma$ Clone B27). The cells were further analyzed using the BD FACS Canto II flow cytometry system (BD Biosciences).

\section{Luciferase gene reporter assay}

The $3^{\prime}$ untranslated region (UTR) of LDHA containing the wild-type or mutant potential target site for miR-34a was synthesized by Genescript (Nanjing, China) and inserted into pGL4.10[luc2] Vector (Promega, Madison, WI, USA). For luciferase assay, Jurkat cells were co-transfected with pGL4-PTPROt-WT 3' UTR or pGL4-PTPROt-MU 3' UTR, with miR-34a or control (GenePharma, China) using Lipofectamine 2000 (Thermo Fisher Scientific). Cells were harvested $48 \mathrm{~h}$ after transfection for luciferase assay using a DualLuciferase® Reporter Assay System (Promega).

\section{Lentiviral production and transfection}

Full-length LDHA and miR-34a were synthesized by Genscript. The sequences were subcloned into pLV-His plasmid, and further packaged for lentiviral particles as previously described [13]. Candidate plasmid was cotransfected with VSV-g and dR8.91 in 293T cells. The supernatant was collected after culture for $72 \mathrm{~h}$. Virus supernatant was concentrated through ultracentrifugation. 


\section{Cellular Physiology Cell Physiol Biochem 2018;49:828-836 \begin{tabular}{ll|l} 
DOI: 10.1159/000493110 & and Biochemistry 2018 The Author(s). Published by S. Karger AG, Basel \\
wuww.karger.com/cpb
\end{tabular}}

Ping et al.: miR-34a Regulate GC T Cell via LDHA

Statistical analysis

Differences between cases and controls were evaluated by Student's $t$-test for continuous variables and the $\chi^{2}$ test for categorical variables. Two values correlations were evaluated by linear correlation analysis and $\mathrm{F}$ test. All statistical analyses were performed using SPSS version 12 software.

\section{Results}

Increased lactate was associated with decreased immune surveillance within GC TILS

An acidic environment is common in cancer, especially in solid tumors, and a recent report indicated that it can cause functional impairment in infiltrating immunocytes [14]. We investigated the difference in acid metabolomics between GC TILs and peripheral T cells in GC patients and healthy controls. GC TILs demonstrated strong glycolysis, but weaker TCA cycle activity compared to the peripheral T cells from the healthy controls. Lactate showed one of the biggest differences between GC TILs and peripheral T cells (Fig. 1A). We verified this difference in peripheral T cells and TILs isolated from 73 GC patients and peripheral T cells from 58 healthy controls. Lactate concentration in TILs was significantly higher than in peripheral $\mathrm{T}$ cells from healthy controls, but no difference was found in the peripheral $\mathrm{T}$ cells from GC patients and healthy controls (Fig. 1B). Lactate level was significantly higher in stage III/IV compared to stage I/II GC (Fig. 1C).

To investigate the relation between T-cell lactate metabolism and function, we divided the GC patients into two groups according to the upper $95 \%$ confidence interval $(\mathrm{CI})$ value of lactate level in the healthy control $\mathrm{T}$ cells (lactate ${ }^{\text {high }}$ $\mathrm{n}=40$, lactate ${ }^{\text {low }} \mathrm{n}=33$ ) (Fig. 1B). We determined the Th1 cell and CTL percentages among GC TILs using flow cytometry. The lactate ${ }^{\text {high }}$ group had lower Th1 cell and CTL percentages compared to the lactate ${ }^{\text {low }}$ group (Fig. 2A, $B)$. Furthermore, lactate level was negatively correlated with Th1 $\left(\mathrm{CD}^{+} \mathrm{IFN} \gamma^{+}\right)(\mathrm{R}=$ -0.0872, $\quad \mathrm{p}=0.0069)$ as well as CTL $\left(\mathrm{CD}^{+} \mathrm{IFN}^{+} \gamma^{+}\right)$ $(\mathrm{r}=\quad-0.0771, \quad \mathrm{p}=0.0115)$ percentages within TILs (Fig. 2 C, D).

Increased LDHA was responsible for increased lactate in GC TILs

We measured expression of LDHA and LDHB in GC TILs. LDHA but not LDHB was significantly increased in GC TILs and peripheral $\mathrm{T}$ cells compared to those from healthy controls (Fig. 3A, B). We compared LDHA expression in GC TILs according to different TNM stages. Stage I/II GC TILs expressed significantly less LDHA than stage III/IV GC TILs (Fig. 3C). We divided the

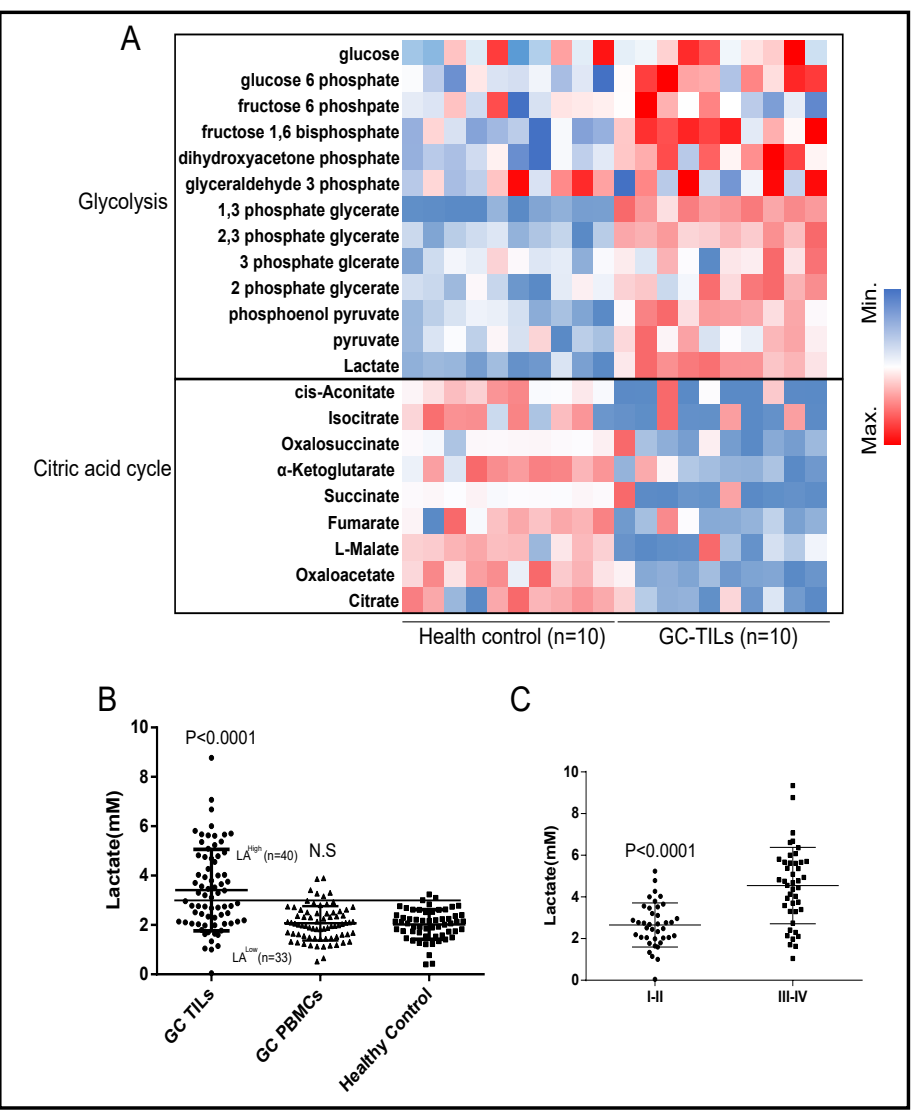

Fig. 1. Lactate significantly increased in GC TILs. A: Hierarchical clustering analysis of glycolysis and TCR cycle related metabolites that are differentially expressed in GC TILs $(n=10)$ and peripheral $\mathrm{T}$ cells $(\mathrm{n}=10)$ isolated from healthy controls (Health control) B: Determination of lactate concentration in GC TILs and T cells in healthy controls. C: Comparison of lactate concentration in GC TILs from GC at different TNM stages. All experiments were performed in triplicate. 
GC patients into two groups according to the upper 95\% CI value of LDHA expression in healthy control T cells (lactate ${ }^{\text {high }} n=43$, lactate ${ }^{\text {low }} n=30$ ). We compared expression of IFN- $\gamma$ and GZMB in these two groups, which indicated that the LDHA ${ }^{\text {low }}$ group expressed significantly more IFN $\gamma \quad(\mathrm{P}=0.0016$, Student's $t$-test) and GZMB $\quad(\mathrm{p}=0.0004$, Student's $t$-test) than the LDHA $^{\text {high }}$ group expressed (Fig. 3D, E). Linear correlation between expression of LDHA and lactate level in TILs was also confirmed, which indicated that lactate level was positively correlated linearly with expression of LDHA in TILs (LDHA vs. LA, $\mathrm{R}=0.5332, \quad \mathrm{p}<0.0001$ ) (Fig. 3F).

We confirmed expression of IFN- $\gamma$ and GZMB using immunohistochemistry staining in GC adjacent normal tissues. Expression of both was significantly higher in the LDHA $^{\text {low }}$ group than in the LDHA ${ }^{\text {high }}$ group (Fig. $4 A$ ). According to the subgroups divided based on the lactate level, we detected expression of LDHA and IFN- $\gamma$ in TILs
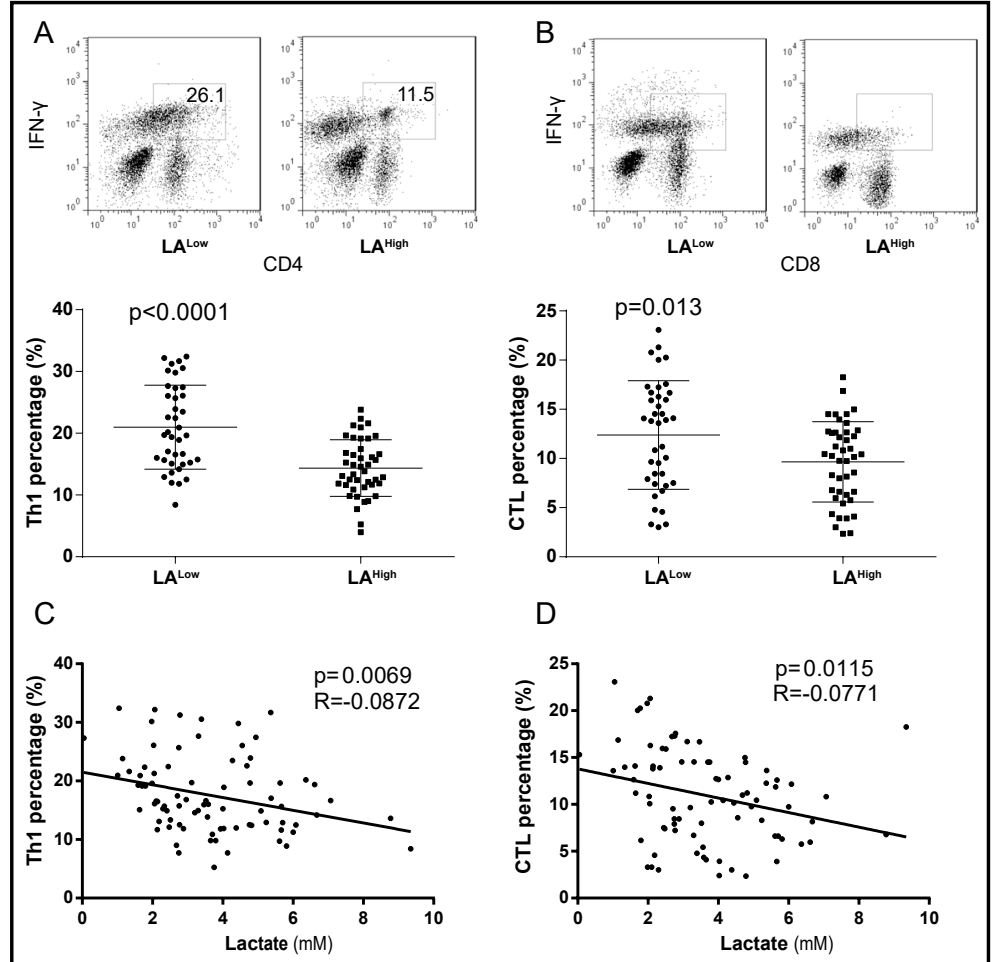

Fig. 2. TIL lactate level was related to percentages of Th1 cells and CTLs among GC TILs. The percentage of Th1 $\left(\mathrm{CD} 4{ }^{+} \mathrm{IFN}-\gamma^{+}\right)$cells and CTLs $\left(\mathrm{CD}^{+} \mathrm{IFN}-\gamma^{+}\right)$in GC TILs was determined using flow cytometry, and comparisons were made between lactate ${ }^{\text {low }}$ and lactate ${ }^{\text {high }}$ groups. The results for Th1 cells and CTLs are presented in A and B, respectively. C and D: Linear correlation was performed between the lactate concentration and IFN- $\gamma$ and GZMB levels in GC TILs. All experiments were performed in triplicate.

Fig. 3. Increased TIL LDHA was related to decreased IFN- $\gamma$ and GZMB production in GC TILs. A, B: Expression of LDHA and LDHB was determined using real-time PCR, and comparison between GC TILs and healthy controls was carried out. C: Expression of LDHA was determined by real-time PCR, and comparison was performed between

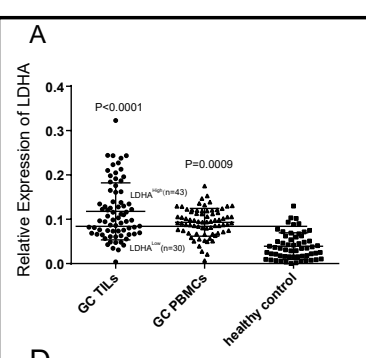

D

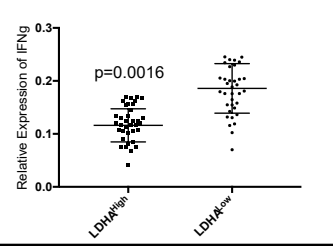

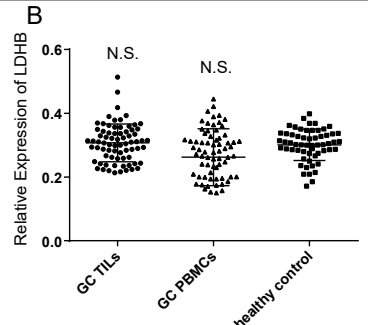

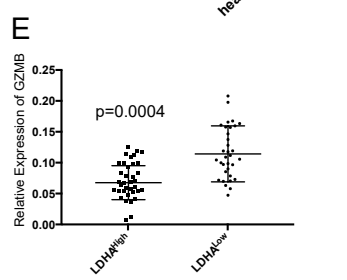

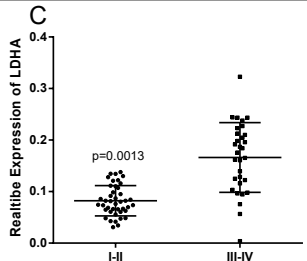

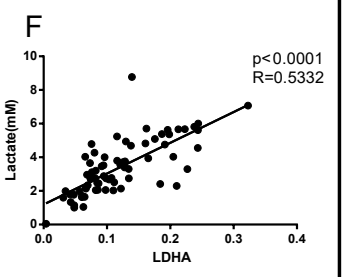

different GC TNM stages. D and E: Expression of IFN- $\gamma$ and GZMB in GC TILs was determined by real-time PCR, and comparison of these two indices was performed between LDHA ${ }^{\text {low }}$ and LDHA ${ }^{\text {ligh }}$ groups. F: Linear correlation was performed between the lactate concentration and LDHA level in GC TILs. All experiments were performed in triplicate. 
Fig. 4. LDHA is related to IFN- $\gamma$ and GZMB protein expression within GC tissues. A: Protein expression of IFN- $\gamma$ and GZMB in human GC and adjacent normal tissue was detected using immunohistochemistry (200×). Integrated optical density was analyzed in five random fields of each slide using Image J. B: IFN- $\gamma$, GZMB and LDHA protein expression in GC TILs in LDHA $^{\text {low }}$ and LDHA ${ }^{\text {high }}$ groups was determined using western blotting. All experiments were performed in triplicate.

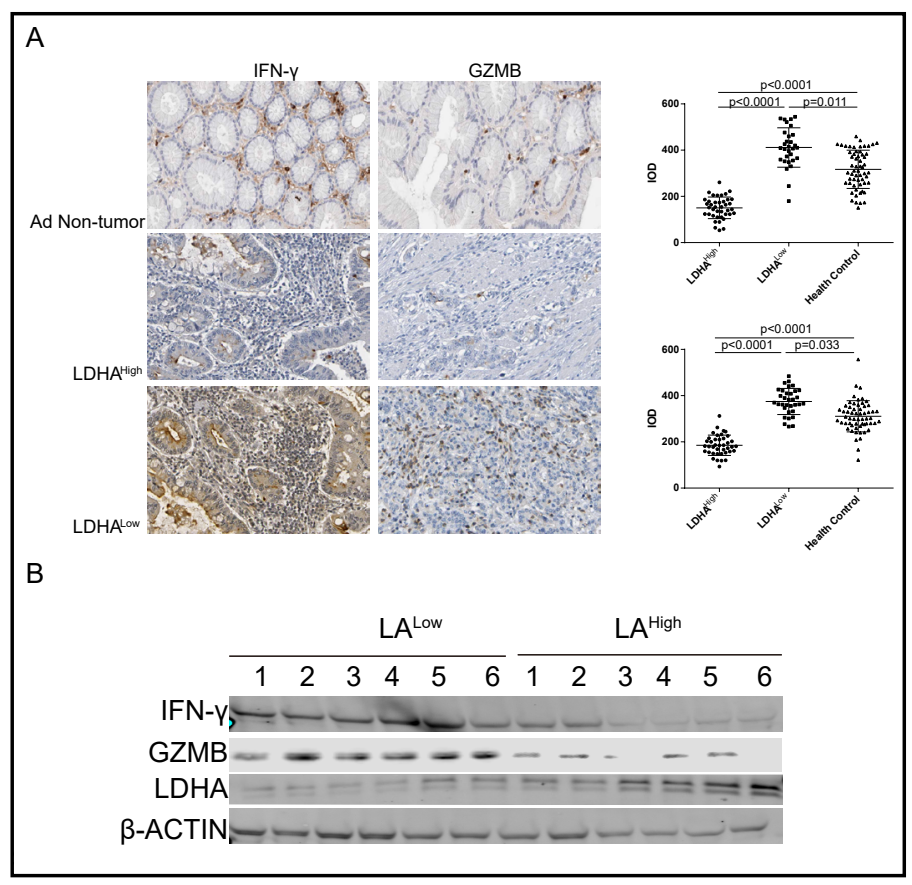

Fig. 5. Decreased expression of miR-34a was responsible for increased lactate concentration and increased LDHA in GC TILs. A and B: Expression of miR-34a was determined in GC TILs and healthy control $\mathrm{T}$ cells. Comparison of miR-34a in GC TILs versus healthy control T cells, and $\mathrm{LDHA}^{\text {low }}$ and LDHA $^{\text {high }}$ groups are presented in A and B, respectively. C: Linear correlation was performed between the miR-34a and LDHA level in GC TILs. D: Luciferase reporter gene assay was performed using both wild type and mutated LDHA 3' UTR transfected by miR-34a and control miRNA. All experiments were performed in triplicate.

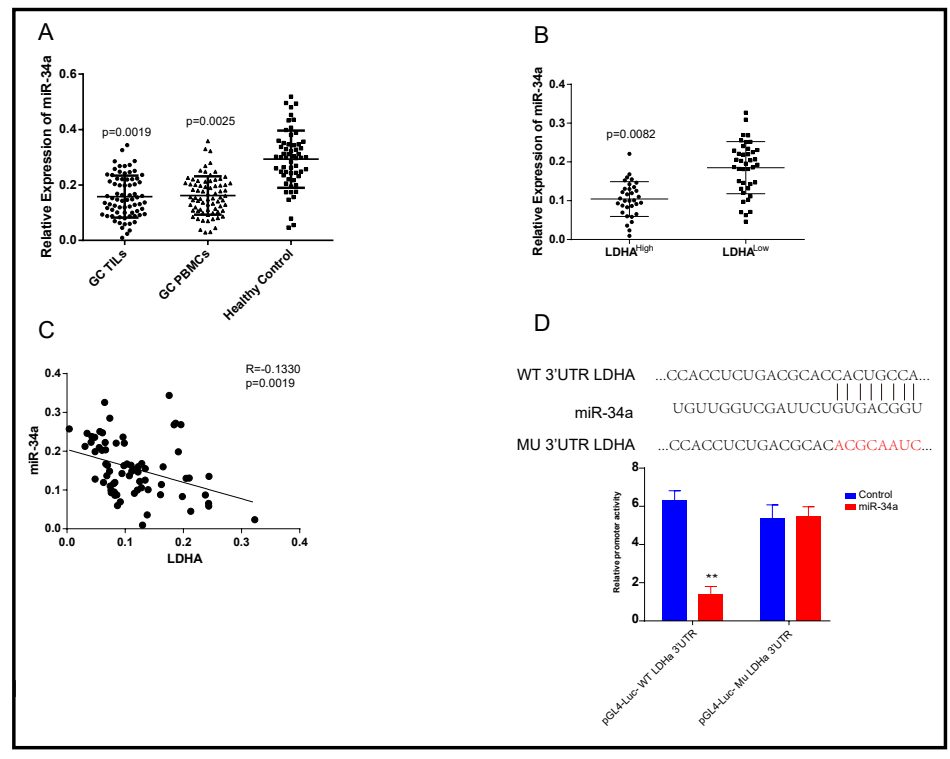

by western blotting ( $\mathrm{n}=6$ for lactate ${ }^{\text {low }}$ and lactate $\mathrm{figh}^{\text {high }}$, respectively). Lactate ${ }^{\text {low }}$ TILs expressed less LDHA and more IFN- $\gamma$ compared to the lactate ${ }^{\text {high }}$ TILs (Fig. 4B).

Decreased expression of miR-34a was responsible for increased lactate concentration and increased LDHA in GC TILS

To investigate the mechanism of increased LDHA in T cells, we detected the expression of miR-34a, which is reported to downregulate LDHA expression by targeting its 3' UTR [15, 16]. miR-34a was significantly decreased in GC TILs and peripheral T cells compared to those from healthy controls (Fig. 5A). Furthermore, significantly lower expression of miR-34a was found in LDHA ${ }^{\text {high }}$ compared to LDHA ${ }^{\text {low }}$ TILs ( $\mathrm{p}=0.0082$, Student's $t$-test) (Fig. 5B). We also found that the expression of miR-34a was negatively correlated with LDHA in GC TILs (LDHA vs. miR-34a, $R=-0.1330, p=0.0019$ ) (Fig. 5C). We confirmed the regulatory effect of miR-34a on LDHA expression by reporter gene assay in Jurkat cells. Mutation of the potential miR34a binding site (406-413) in the LDHA 3' UTR increased the promoter activity that can be 
significantly suppressed by wildtype 3' UTR (Fig. 5D).

Overexpression of miR-34a decreased LDHA and lactate and increased IFN $\gamma$ and GZMB expression in T cells

$\mathrm{T}$ cells were isolated from healthy controls $(\mathrm{n}=6)$ and activated using $5 \mu \mathrm{g} / \mathrm{mL}$ Con A (48 h), $5 \mathrm{mM}$ lactate (for $48 \mathrm{~h}$ ) and hypoxia $\left(1 \% \mathrm{O}_{2}\right.$ for $\left.48 \mathrm{~h}\right)$ to investigate their effects on expression of miR-34a, LDHA and IFN- $\gamma$ production. Con $\mathrm{A}$ and lactate had no effect on miR-34a and LDHA expression in T cells. However, hypoxia increased LDHA and decreased miR-34a expression. Overexpression of miR-34a decreased expression of LDHA and increased expression of IFN- $\gamma$. Overexpression of LDHA decreased IFN- $\gamma$ production in $\mathrm{T}$ cells with miR-34a overexpression (Fig. 6A). A ConA stimulation assay was performed under hypoxic conditions. Overexpression of miR34a increased IFN- $\gamma$ and GZMB expression but can be restored by LDHA overexpression in $\mathrm{T}$ cells, which was verified using real-time PCR and western blotting (Fig. 6B and $\mathrm{C}$ ). Lactate level decreased significantly with overexpression of miR-34a, and was also restored by overexpression of LDHA (Fig. 6D).

In summary, our study indicated that decreased miR-34a in GC TILs impaired T-cell immune surveillance in lactate-abundant tumors by upregulation of LDHA.

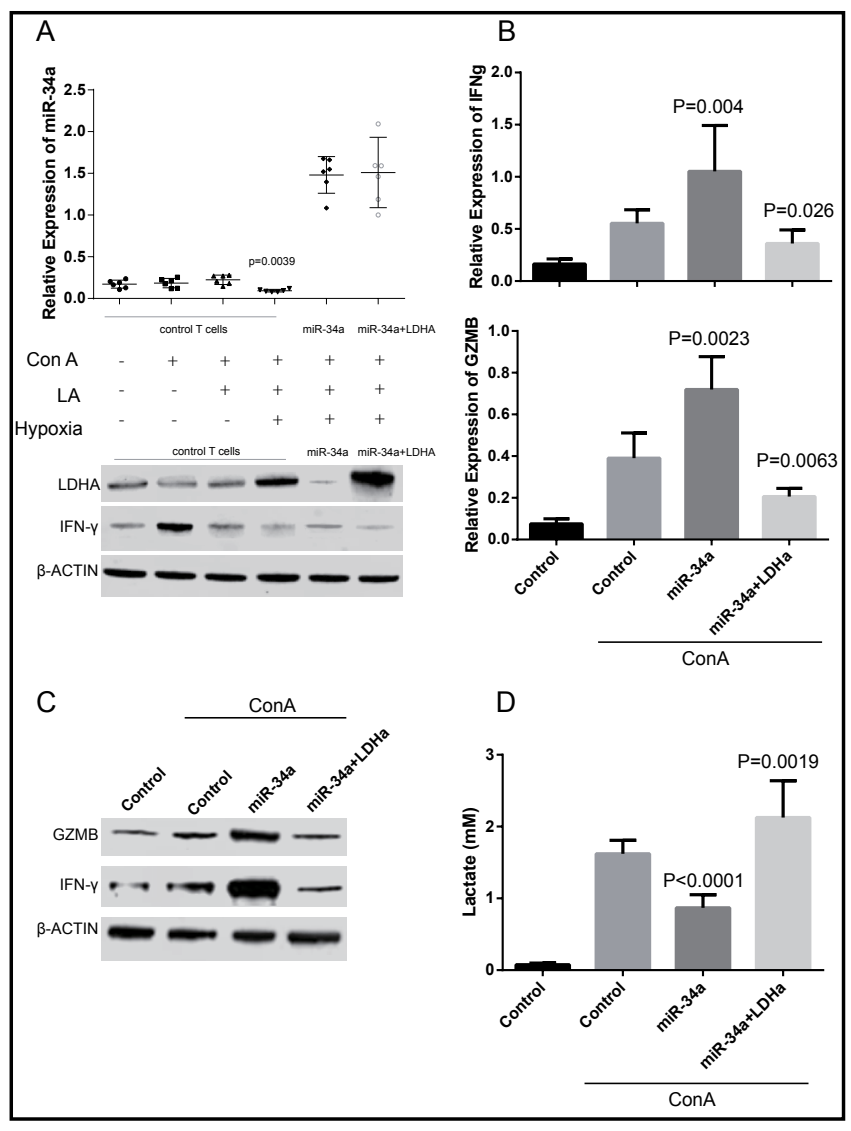

Fig. 6. Overexpression of miR-34a decreased LDHA and lactate level and increases IFN- $\gamma$ and GZMB expression in T cells. A: T cells isolated from healthy controls were treated as indicated. Transcription of miR-34a and expression of LDHA and IFN- $\gamma$ were compared between different groups. B and C: Transcription and protein expression of IFN- $\gamma$ and GZMB in T cells were assessed using real-time PCR and western blotting, respectively. Comparison of IFN- $\gamma$ and GZMB expression determined by realtime PCR was performed between ConA-treated control T cells and ConA treated T cells transduced differently. D: Lactate level in T cells treated differently according to the figure was assessed. All experiments were performed in triplicate. Comparison of lactate level was performed between ConA treated control $\mathrm{T}$ cells and ConA treated $\mathrm{T}$ cells transduced differently.

\section{Discussion}

Lactate (2-hydroxypropanoic acid) is a 3-carbon hydroxycarboxylic acid that may exist as two stereoisomers, D-lactate, and L-lactate; the latter being the predominant physiological enantiomer. Lactic acid has the formula $\mathrm{CH}_{3} \mathrm{CH}(\mathrm{OH}) \mathrm{CO}_{2} \mathrm{H}$. The anion lactate $\mathrm{CH}_{3} \mathrm{CH}(\mathrm{OH}) \mathrm{CO}_{2}{ }^{-}$ is the predominant moiety present in the human body, as the pKa of the lactate/lactic acid pair is $3.8[15,17,18]$. Pyruvate is the final product of glycolysis, yielding two moles of ATP for each molecule of glucose in the process [17]. Under normoxic conditions, pyruvate is converted by pyruvate dehydrogenase into acetyl-CoA, which enters into the TCA or Krebs cycle. Under anaerobic conditions, pyruvate is converted to lactic acid by LDH [19]. Most of the previous studies focused on the Warburg effect, which means enhanced glycolysis in tumor cells, indicating their special metabolic model [20]. T-cell activation also has a different metabolic model, namely, activation of T cells through T-cell receptor (TCR)- and CD28-mediated co-stimulation leads to a rapid increase in expression of glucose transporter GLUT-1, glucose uptake, and glycolysis [10]. However, we found that the accumulation of 


\section{Cellular Physiology Cell Physiol Biochem 2018;49:828-836 \begin{tabular}{l|l|l} 
and Biochemistry 10.1159/000493110 & $\begin{array}{l}\text { C } 2018 \text { The Author(s). Published by S. Karger AG, Basel } \\
\text { www.karger.com/cpb }\end{array}$
\end{tabular}}

Ping et al.: miR-34a Regulate GC T Cell via LDHA

lactate might cause functional impairment of T cells. TILs also had enhanced glycolysis and increased lactate. The increased lactate was related to decreased immune surveillance that was reflected as decreased percentages of Th1 cells and CTLs. Our findings were similar to previous studies. Brand et al. reported that pathophysiological concentrations of lactic acid prevented upregulation of NFAT in T and natural killer cells, resulting in diminished IFN- $\gamma$ production. Database analyses revealed negative correlations between LDHA expression and T-cell activation markers in human melanoma patients [11]. These results were similar to ours in that LDHA in T cells increased and contributed to the de novo synthesis of lactate, but the reason for increased LDHA has rarely been addressed. We found that miR-34a expression was decreased in T cells, which contributed to the increase in LDHA in human GC TILs. Several studies have revealed that LDHA is one of the target genes of miR-34a in different cancer tissues including breast cancer and colorectal cancer (CRC) [15, 16, 21]. Our results also indicated a similar outcome in that miR-34a downregulated LDHA expression in T cells.

The miR-34 family members comprise three processed miRs that are encoded by two different genes: miR-34a is encoded by its own transcript, whereas miR-34b and miR-34c share a common primary transcript [22-24]. Various transcription factors have been shown to regulate miR-34a expression. One of the strongest inducers of miR-34a is p53. In contrast, hypoxia-inducible factor (HIF)-1 $\alpha$ is also reported to have an antagonistic effect on its transcription [23]. HIF-1 $\alpha$ directly repressed the MIR34A gene in p53-defective CRC cells, whereas expression of MIR34A was induced in p53-proficient CRC cells exposed to hypoxia. Downregulation of MIR34A was required for hypoxia-induced epithelial-mesenchymal transition, invasion and migration, and activation of signal transducer and activator of transcription in CRC cells $[25,26]$. Our results were similar. We found that increasing lactate alone did not decrease miR-34a transcription unless hypoxia was involved.

In summary, our results provided a novel discovery of increased lactate level in GC TILs, and the increased lactate level was related to impaired T-cell function due to increased LDHA-induced de novo lactate synthesis. Also, increased LDHA expression in peripheral T cells might be regarded as a bystander marker for immunosuppression. The increased LDHA in T cells was due to decreased hypoxia-induced miR-34a expression. T cell LDHA and miR34 a might be valuable therapeutic targets in gene therapy in the future.

\section{Disclosure Statement}

The authors declare to have no competing interests.

\section{References}

1 Corbet C, Feron 0: Tumour acidosis: from the passenger to the driver's seat. Nat Rev Cancer 2017;17:577593.

2 Ganapathy-Kanniappan S: Taming Tumor Glycolysis and Potential Implications for Immunotherapy. Front Oncol 2017;7:36.

-3 Anderson KG, Stromnes IM, Greenberg PD: Obstacles Posed by the Tumor Microenvironment to T cell Activity: A Case for Synergistic Therapies. Cancer Cell 2017;31:311-325.

4 Singer K, Gottfried E, Kreutz M, Mackensen A: Suppression of T-cell responses by tumor metabolites. Cancer Immunol Immunother 2011;60:425-431.

-5 Ratnikov BI, Scott DA, Osterman AL, Smith JW, Ronai ZA: Metabolic rewiring in melanoma. Oncogene 2017;36:147-157.

Buck MD, Sowell RT, Kaech SM, Pearce EL: Metabolic Instruction of Immunity. Cell 2017;169:570-586. Kimmelman AC, White E: Autophagy and Tumor Metabolism. Cell Metab 2017;25:1037-1043.

-8 Marchiq I, Pouyssegur J: Hypoxia, cancer metabolism and the therapeutic benefit of targeting lactate/H(+) symporters. J Mol Med (Berl) 2016;94:155-171.

-9 Calcinotto A, Filipazzi P, Grioni M, Iero M, De Milito A, Ricupito A, Cova A, Canese R, Jachetti E, Rossetti M, Huber V, Parmiani G, Generoso L, Santinami M, Borghi M, Fais S, Bellone M, Rivoltini L: Modulation of microenvironment acidity reverses anergy in human and murine tumor-infiltrating $\mathrm{T}$ lymphocytes. Cancer Res 2012;72:2746-2756. 


\section{Cellular Physiology Cell Physiol Biochem 2018;49:828-836 \begin{tabular}{ll|l} 
DOI: 10.1159/000493110 & $\begin{array}{l}\text { O 2018 The Author(s). Published by S. Karger AG, Basel } \\
\text { www.karger.com/cpb }\end{array}$ \\
\hline
\end{tabular}}

Ping et al.: miR-34a Regulate GC T Cell via LDHA

10 Caro-Maldonado A, Wang R, Nichols AG, Kuraoka M, Milasta S, Sun LD, Gavin AL, Abel ED, Kelsoe G, Green $\mathrm{DR}$, Rathmell JC: Metabolic reprogramming is required for antibody production that is suppressed in anergic but exaggerated in chronically BAFF-exposed B cells. J Immunol 2014;192:3626-3636.

11 Brand A, Singer K, Koehl GE, Kolitzus M, Schoenhammer G, Thiel A, Matos C, Bruss C, Klobuch S, Peter K, Kastenberger M, Bogdan C, Schleicher U, Mackensen A, Ullrich E, Fichtner-Feigl S, Kesselring R, Mack M, Ritter U, Schmid M, et al.: LDHA-Associated Lactic Acid Production Blunts Tumor Immunosurveillance by T and NK Cells. Cell Metab 2016;24:657-671.

12 Kuang DM, Peng C, Zhao Q, Wu Y, Chen MS, Zheng L: Activated monocytes in peritumoral stroma of hepatocellular carcinoma promote expansion of memory T helper 17 cells. Hepatology 2010;51:154-164.

13 Lin CS, Lee HT, Lee MH, Pan SC, Ke CY, Chiu AW, Wei YH: Role of Mitochondrial DNA Copy Number Alteration in Human Renal Cell Carcinoma. Int J Mol Sci 2016;17:pii:E814.

14 Vijayan D, Young A, Teng MWL, Smyth MJ: Targeting immunosuppressive adenosine in cancer. Nat Rev Cancer 2017;17:709-724.

$\checkmark 15$ Li X, Zhao H, Zhou X, Song L: Inhibition of lactate dehydrogenase A by microRNA-34a resensitizes colon cancer cells to 5-fluorouracil. Mol Med Rep 2015;11:577-582.

-16 Xiao X, Huang X, Ye F, Chen B, Song C, Wen J, Zhang Z, Zheng G, Tang H, Xie X: The miR-34a-LDHA axis regulates glucose metabolism and tumor growth in breast cancer. Sci Rep 2016;6:21735.

$>17$ Wang J, Wang H, Liu A, Fang C, Hao J, Wang Z: Lactate dehydrogenase A negatively regulated by miRNAs promotes aerobic glycolysis and is increased in colorectal cancer. Oncotarget 2015;6:19456-19468.

18 Wang J, Yan S, Zhang W, Zhang H, Dai J: Integrated proteomic and miRNA transcriptional analysis reveals the hepatotoxicity mechanism of PFNA exposure in mice. J Proteome Res 2015;14:330-341.

-19 Flores A, Schell J, Krall AS, Jelinek D, Miranda M, Grigorian M, Braas D, White AC, Zhou JL, Graham NA, Graeber T, Seth P, Evseenko D, Coller HA, Rutter J, Christofk HR, Lowry WE: Lactate dehydrogenase activity drives hair follicle stem cell activation. Nat Cell Biol 2017;19:1017-1026.

-20 San-Millan I, Brooks GA: Reexamining cancer metabolism: lactate production for carcinogenesis could be the purpose and explanation of the Warburg Effect. Carcinogenesis 2017;38:119-133.

-21 Kaller M, Liffers ST, Oeljeklaus S, Kuhlmann K, Roh S, Hoffmann R, Warscheid B, Hermeking H: Genomewide characterization of miR-34a induced changes in protein and mRNA expression by a combined pulsed SILAC and microarray analysis. Mol Cell Proteomics 2011;10:M111.010462.

-22 Farooqi AA, Fayyaz S, Shatynska-Mytsyk I, Javed Z, Jabeen S, Yaylim I, Gasparri ML, Panici PB: Is miR-34a a Well-equipped Swordsman to Conquer Temple of Molecular Oncology? Chem Biol Drug Des 2016;87:321334.

23 Rokavec M, Li H, Jiang L, Hermeking H: The p53/miR-34 axis in development and disease. J Mol Cell Biol 2014;6:214-230.

24 Rottiers V, Naar AM: MicroRNAs in metabolism and metabolic disorders. Nat Rev Mol Cell Biol 2012;13:239-250.

25 Lin Y, Shen J, Li D, Ming J, Liu X, Zhang N, Lai J, Shi M, Ji Q Xing Y: MiR-34a contributes to diabetes-related cochlear hair cell apoptosis via SIRT1/HIF-1alpha signaling. Gen Comp Endocrinol 2017;246:63-70.

-26 Tafsiri E, Darbouy M, Shadmehr MB, Cho WC, Karimipoor M: Abberent expression of oncogenic and tumorsuppressive microRNAs and their target genes in human adenocarcinoma alveolar basal epithelial cells. J Cancer Res Ther 2016;12:395-400. 